Milan Moravcik*

\title{
ACCELERATION RESPONSE OF THE RAILWAY BRIDGES -VERIFICATION OF THE LIMIT STATE OF ACCELERATION
}

The dynamic response of a girder bridge under trains is studied with an emphasis on the vertical track acceleration. The vehicles are modelled as a series of moving loads. The efficiency of the method is demonstrated on the simply supported railway bridge of the length $L_{b}=38 \mathrm{~m}$ subjected to the series of the bogie forces of the conventional IC train. The closed-form solution of the bridge response with the intention to resonance and cancellation effects is applied. The acceleration response is investigated for the resonance train speed $c=65 \mathrm{~m} / \mathrm{s}=234 \mathrm{~km} / \mathrm{h}$, considering the modes of vibration $j=1$ and $j=1+3$, because higher modes can have significant influence on the acceleration amplitude. The limits of acceleration due to the ballast stability and the traffic safety are evaluated.

Keywords: dynamic response of the railway bridges, acceleration, resonant speed, modal superposition method

\section{Introduction}

Dynamic response of railway bridges subjected to the real trains moving at the speed $c$ most often via the dynamic displacement ${ }^{(c)} w(x, t)$ and the vertical acceleration ${ }^{(c)} \ddot{w}(x, t)$ . In this direction, the most analyses are formed for the load considered as a single point load (the axle loads $P_{a x}$ or the bogie loads $P_{b g}$ ) [1-4], but the practical case of the response corresponds to the passage of whole train. At present time, the actual question becomes vibrations of railway bridges due to the train moving at speeds above $200 \mathrm{~km} / \mathrm{h}$. It poses dynamic problems of higher order, due to the possibility of resonance effects and their possible limitation. The presented numeric study is focused to the loads by conventional IC passenger trains running on the Slovak railways lines, Figure 1.

In this study, the acceleration response of the small and medium weakly damped bridges ( $\xi_{d}<0.05$ ), modelled as a simply supported 2D beam, subjected to a row of bogie forces $P_{b g, n}$, $n=1,2, \ldots . N$ of IC-cars is presented. The acceleration response is focussed on the mid-point response for the train speed $c$ and will be marked in the form ${ }^{(c)} \ddot{w}_{(j),\left(P_{b y n}\right)}\left(L_{b} / 2, t\right)$, considering modes of vibrations $j=1$ and $j=1+3$ because higher modes can impose significant influence on the acceleration amplitude. The response will be analysed with the purpose to evaluate the effect of individual components of the acceleration on the total vertical acceleration. Typical cross sections of the railway bridge are shown in Figure 2. The vertical plane of symmetry of the crosssection coincides with the track axes, which is the plane of the bridge vibrations.

The solution of the problem is presented for the real railway steel bridge of the length $L_{b}=38 \mathrm{~m}$ subjected by the whole passenger train with eight IC cars for one resonance speed $c=65$ $\mathrm{m} / \mathrm{s}=234 \mathrm{~km} / \mathrm{h}$.
The spacing length between concentrated bogie loads $P_{b g, n}$ corresponds to full length $d_{c h}=d_{v}=24.5 \mathrm{~m}$ of the IC-carriage (the conventional passenger IC-car of Slovak IC-trains) as is shown in Figure 1.

\section{Resonance and cancellation conditions of the bridge}

The resonance conditions belongs to the periodic excitation of concentrated loads moving over a bridge, can be obtained from the theoretical solution of the vertical vibrations of the beam subjected to a moving load series [5-7]. The resonant condition is calculated from the time necessary for crossing the characteristic length $d_{c h}$ at speed $c$, which is equal to the $k$-multiple of the period of natural vibrations $T_{j}=\frac{1}{f_{j}}=\frac{2 \pi}{\omega_{j}}$, for $j=1,2,3, \ldots$ and gives

$f_{e x}=f_{(j)} k=\frac{\omega_{(j)}}{2 \pi} k, k=1,2,3, \ldots$,

where: $f_{e x}=\frac{c}{d_{v}}$ is the excitation frequency.

\section{A) Resonant speed}

For simply supported bridges it is significant that the fundamental mode $\omega_{(1)}=2 \pi f_{(1)}$ provides the largest contribution to the response and from the resonant condition (2) results the resonant train speeds $c_{(k) r e s}$ :

$c_{(k) \text { res }}=\frac{\omega_{(1)} d_{v}}{k 2 \pi}=\frac{f_{(1)} d_{v}}{k}[\mathrm{~m} / \mathrm{s}], k=1,2,3, \ldots$.

Each load force $P_{b g, n}, n=1,2,3, \ldots . N$ in a moving load series may induce the transient response of the bridge and the successive forces $P_{b g, n+1}$ form a periodical excitation. The response will be successively amplified with increase of the number of forces

\footnotetext{
* Milan Moravcik

Faculty of Civil Engineering, University of Zilina, Slovakia

E-mail:mimo@fstav.uniza.sk
} 


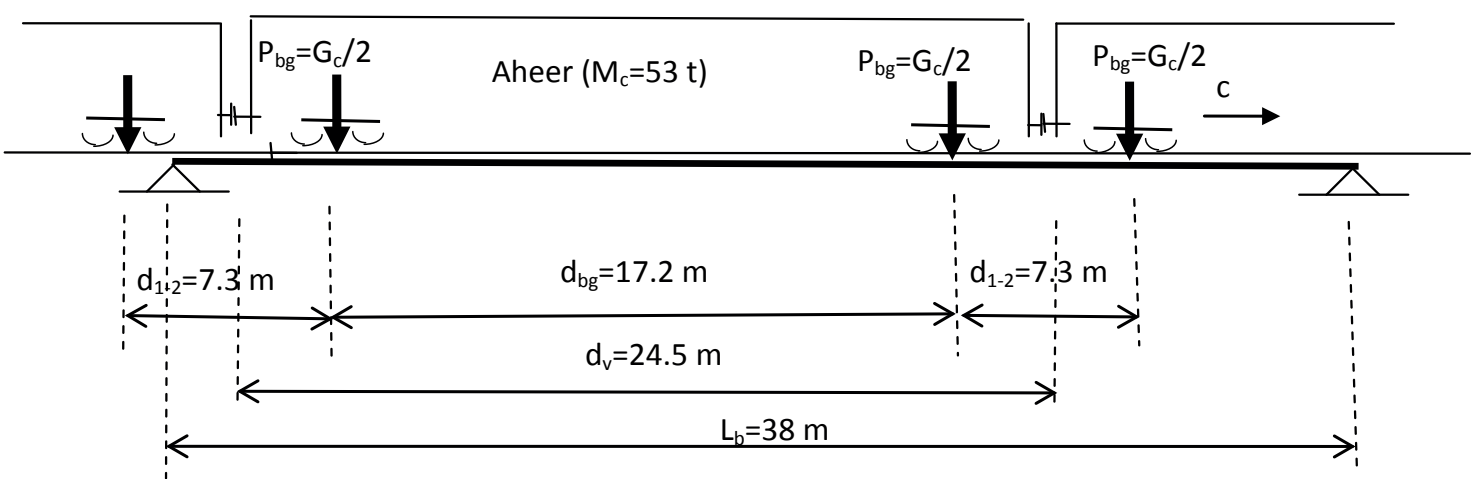

Figure 1 Simply supported bridge subjected to series moving loads - the bogie loads of IC-cars
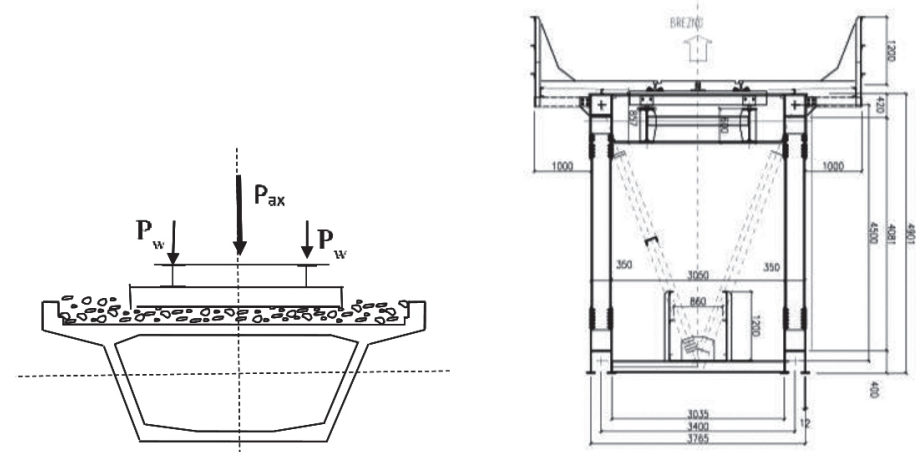

Figure 2 Typical cross sections of the railway bridges

travelling through the beam. The real resonant speed (2) is also affected by the span velocity ratio [6]

$\cos \left(\omega_{(1)} L_{b} / c_{(k) r e s}\right)$.

If the condition (3) approaches the value -1.0 , the resonant amplitude may be suppressed.

For example, the resonant train speed $c_{(k=2) \text { res }}$ for the bridges of the length $L_{b}=38 \mathrm{~m}$, and $d=24.5 \mathrm{~m}$, and for $\omega_{(1)}=\frac{\pi^{2}}{L_{b}^{2}} \sqrt{\frac{E I}{m_{1}}}=33.34 s^{-1}$ is $c_{(k=2)}=\frac{\omega_{(1)} d_{v}}{k \cdot 2 \pi}=65 \mathrm{~m} / \mathrm{s}=$ $234 \mathrm{~km} / \mathrm{h}$ and the span velocity ratio and $\cos \left(\omega_{(1)} L_{b} / c_{2}\right)=0.8072$.

\section{B) Cancellation of the resonance}

Unlike the resonance effect that enlarges the bridge response, the cancellation effect may suppress the vibrations of the bridge. The cancellation phenomenon implies that the waves associated with the free vibrations response of the bridge cancel out each other. For a load series, the condition of cancellation of the resonance vibrations results from the general solution of the dynamic response and gives the condition which is defined in [6] as the first type of the vibrations cancellation:

$$
\cos \left(\frac{\omega_{(1)} d}{2 c}\right)=0, \frac{\omega_{(1)} d}{2 c}=\frac{\pi(2 k-1)}{2}, k=1,2,3, \ldots
$$

where: $d=\left(d_{v}, d_{c P}, d_{c 2}\right)$ is the characteristic interval of the load series (Figure 1). This type of cancellation is induced by each individual load and is independent on the composition of the load series.

For example: For the considered case $\mathrm{L}_{\mathrm{b}}=38 \mathrm{~m}$, $\omega_{(1)}=33.34 s^{-1}, \quad d_{c h}=d_{v}=24.5 m$ and for $k=3$ the cancellation speed is $c_{(3) \text { can }}=\frac{33.34 \cdot 24.5}{(2 \cdot 3-1) \pi}=52 \mathrm{~m} / \mathrm{s}^{2}=187.3$
$\mathrm{~km} / \mathrm{h}$.

\subsection{Serviceability limit state - traffic safety}

The limits of vibrations and deformation in railway bridges should be reviewed and evaluated just over acceleration of the bridge. Excessive deformations and vibrations can endanger the track geometry, the ballast stability and functionality of the trainbridge. In EN1991-2 [7-8], the criteria for the traffic safety are defined taking into account the following dynamic effects: the vertical acceleration, the vertical deformations and vibrations, the deck twist, and longitudinal displacements.

The maximum peak values for the bridge deck acceleration should not exceed the following values:

1) ${ }^{(c)} \ddot{w}(x, t)_{\max }=3.5-\mathrm{m} / \mathrm{s}^{2}$ for ballasted tracks,

2) ${ }^{(c)} \ddot{w}(x, t)_{\max }=5.0=5.0-\mathrm{m} / \mathrm{s}^{2}$ for direct fastened tracks.

\section{Formulation of the acceleration response} of the beam

The elementary theoretical model for bridges used in the bridge dynamics is considered as a simple beam of span $L_{b}$ subjected to a row of moving forces $P_{n}, n=1,2, \ldots . \mathrm{N}$, which are moving at a constant speed $c$ (Figure 3). The governing BernoulliEuler partial differential equation describes the behaviour of the beam (without the damping term) - the transverse beam deflection $w(x, t)$ due to a series of moving forces: 


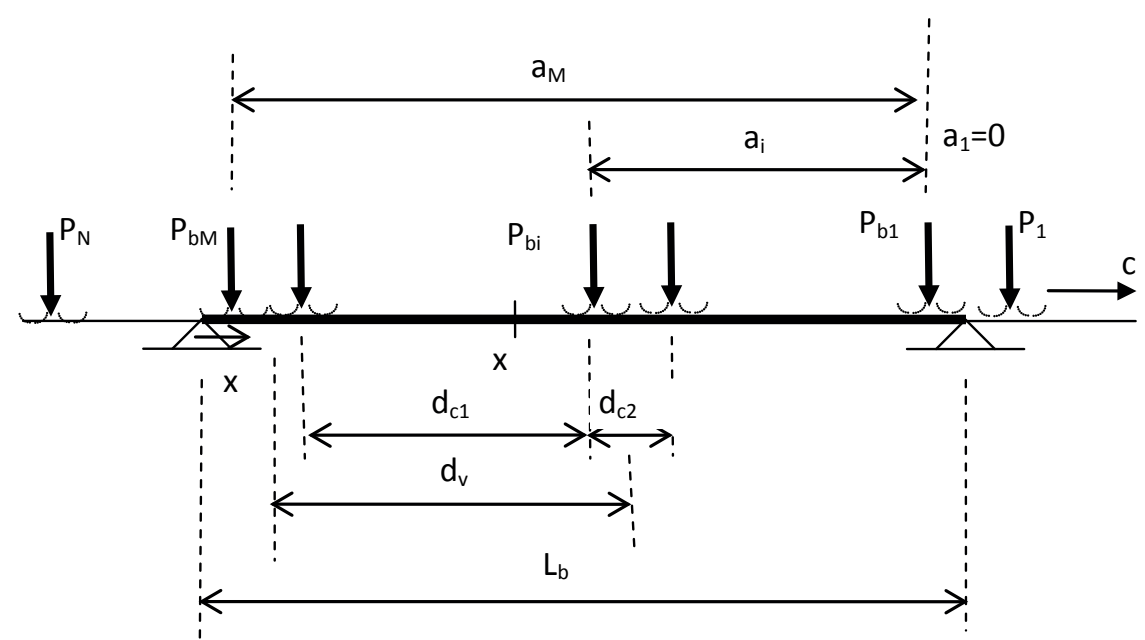

Figure 3 Simple beam of the span $L_{b}$ subjected to a row of forces $P_{n^{\prime}} n=1,2, \ldots . N$, which are moving at a constant speed $c$
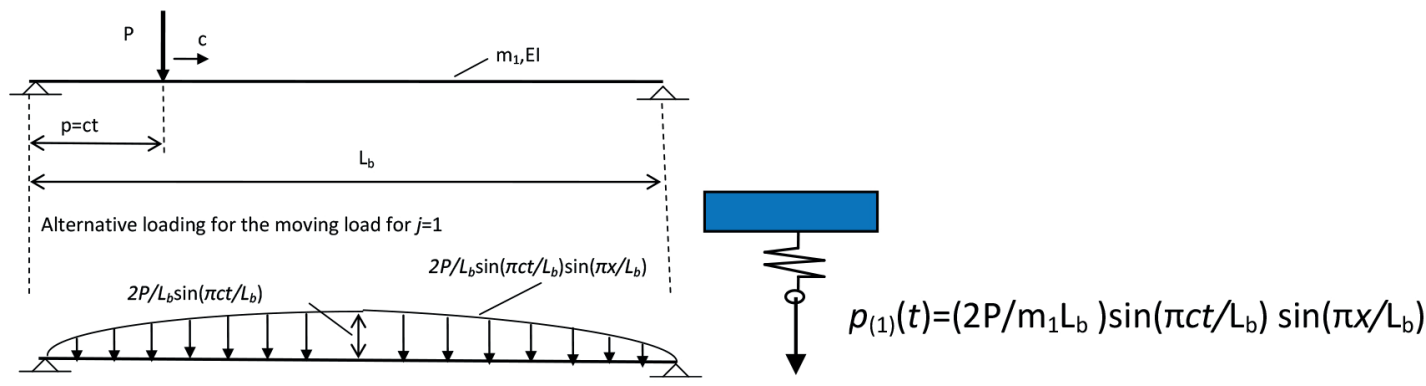

Figure 4 Replacing of the single moving load $P \delta(x-c t)$ by the fixed load $p_{(1)}(t)$

$E I \frac{\partial^{4} w(x, t)}{\partial x^{4}}+m_{1} \frac{\partial^{2} w(x, t)}{\partial t^{2}}=\sum_{n=0}^{M-1} P \delta\left(x-c\left(t-\frac{d_{v, n}}{c}\right) H_{(n)}\right.$, $n=1,2, \ldots . M$

where: $H_{(n)}(t)=\left(\theta\left(t-\frac{d_{b g, n}}{c}\right)-\theta\left(t-\frac{d_{b g, n}}{c}-\frac{L_{b}}{c}\right)\right)$ is the Heaviside function, $\delta(x-c t)$ is the Dirac function.

The solution to Equation (5) can be expressed in terms of the modal shapes $\phi_{(j)}(x)$ and associated modal coordinates $q_{(j)}(t)$ as in [1-2]:

$w(x, t)=\sum_{j} q_{(j)}(t) \cdot \phi_{j}(x)=\sum_{j} q_{(j)}(t) \sin \left(\frac{j \pi x}{L_{b}}\right)$,

$j=1,2,3, \ldots$

where: $q_{(j)}(t)$ are the generalized coordinates that define the amplitude of vibrations, $\phi_{j}(x)=\sin \left(\frac{j \pi x}{L b}\right)$ are the fundamental mode shapes known and for the simply supported beam of a sinusoidal type.

The modal equation corresponding to a general concentrated moving load $P \delta(x-c t)$ corresponds to the solution an one degree of freedom (1DOF) system for the $j$ th mode of vibrations and can be expressed as

$\ddot{q}_{(j)}(t)+\omega_{(j)}^{2} q_{(j)}(t)=\frac{2 P}{m_{1} L_{b}} \sin \frac{j \pi p}{L_{b}}, p=c t$
The constant moving load $P \delta(x-c t)$ (considering only the fundamental shape $j=1$ ) can be replaced by the fixed load $p_{(1)}(t)$ variables over time, Figure 4.

The $j$-th generalized equation of motion of the beam (without damping) corresponding (5) can be written in the form $[1,7]$

$$
\frac{d^{2} q_{(j)}(t)}{d t^{2}}+\omega_{(j)}^{2} q_{(j)}(t)=\frac{2 P}{m_{1} L_{b}} \sum_{n=0}^{M-1} \sin \frac{j \pi p}{L_{b}} .
$$$$
\cdot\left(t-\frac{d_{v, n}}{c}\right) H_{(n)}
$$

$$
\text { for } n=1,2, \ldots . M, 0 \leq t \leq L_{b} / c
$$

Since the maximum acceleration was expected at the midpoint of the beam, the acceleration response was focused on the mid-point response $x=L_{b} / 2$ and it was obtained by superposition of components of the acceleration dependence on number of modes of vibrations $(j)$ acceleration. While for the displacement response modes of vibrations higher than $j=1$ may be neglected without serious loss of accuracy, for the acceleration response of the beam higher modes can have significant influence on the acceleration amplitude.

\subsection{Vertical mid-span acceleration for modes of vibrations $j=1$ and $j=1+3$}

Solution of the problem begins with displacement ${ }^{(c)} w(x, t)$ of the bridge that is expressed in term of the vibrations mode shapes $j$ as follows $[1,7]$. Corresponding acceleration response 
${ }^{(c)} \ddot{w}(x, t)$ can be obtained by differentiating the displacement ${ }^{(c)} w(x, t)$ twice with respect to the time:

$$
{ }^{(c)} \ddot{w}(x, t)=\frac{d^{2}}{d t^{2}}\left[{ }^{(c)} w(x, t)\right]
$$

The acceleration response is marked as ${ }^{(c)} \ddot{w}_{(j),\left(P_{b y n}\right)}\left(L_{b} / 2, t\right)$ and was analysed for the purpose to evaluate the impact of individual components on the total response with the following labelling:

A) The midpoint acceleration - ${ }^{(c)} \ddot{w}_{(j),(P b g, n)}^{(A)}\left(L_{b} / 2, t\right)$, for modes $j$ due to the bogie loads $P_{b g, n}, n=1,2,3, \ldots . M$, moving direct over the beam, ignoring the difference between the damped and un-damped vibrations, which includes the two components:

- Forced vibrations part (the quasi-static component)

${ }^{(c)} \ddot{w}_{(j) s t,(P b g, n)}\left(L_{b} / 2, t\right)$

- Free vibrations part (the dynamic component)

${ }^{(c)} \ddot{w}_{(j) d y n,(P b g, n)}\left(L_{b} / 2, t\right)$.

B) The midpoint acceleration - the free vibrations of the beam ${ }^{(c)} \ddot{w}_{(j),(P b g, n)}^{(B)}\left(L_{b} / 2, t\right)$ due to loads $P_{b g, n}, n=1,2,3, \ldots$. $K$ moving out the beam after they have left the span.

C) The complex midpoint acceleration ${ }^{(c)} \ddot{w}_{(j),(P b, n)}^{(C)}\left(L_{b} / 2, t\right)$ due to the loads $n=1,2, \ldots . M$ moving direct over the beam and the loads $n=1,2, \ldots . K$ moving out the beam after they have left the beam and it can be expressed by the superposition:

$$
\begin{aligned}
& { }^{(c)} \ddot{w}_{(j),(P b g, n)}^{(C)}\left(L_{b} / 2, t\right)={ }^{(c)} \ddot{w}_{(j),(P b g, n)}^{(A)}\left(L_{b} / 2, t\right)+ \\
& +{ }^{(c)} \ddot{w}_{(j) d y n,(P b g, n)}^{(B)}\left(L_{b} / 2, t\right)={ }^{\left({ }^{(B)}\right.} \ddot{w}_{(j) s t,(P b b, n)}\left(L_{b} / 2, t\right)+ \\
& +{ }^{(c)} \ddot{w}_{(j) d y,(P b g, n)}\left(L_{b} / 2, t\right)+\ddot{w}_{(j) d y y_{,}\left(P b_{g}, n\right)}^{(B)}\left(L_{b} / 2, t\right)
\end{aligned}
$$

\subsection{Vertical mid-span acceleration due to the loads moving direct over the beam}

Components of the vertical mid-span acceleration can be written in the form:

A) Component of the acceleration ${ }^{\left({ }^{(c)}\right.} \ddot{\mathcal{w}}_{(j),(P b g, n)}^{(A)}\left(L_{b} / 2, t\right)$, for $j=1+3 \ldots, n=1,2, \ldots . M$ bogie forces moving direct over the beam at speed $c$ and can be expressed as [7] (the damping of the beam is not considered):

$$
\begin{aligned}
& { }^{(c)} \ddot{w}_{(j),(P b g, n)}^{(A)}\left(L_{b} / 2, t\right)=\frac{d^{2}}{d t^{2}}\left[{ }^{(c)} w_{(j),\left(P_{b, n}\right)}^{(2) *}\left(L_{b} / 2, t\right)\right]= \\
& =\frac{d^{2}}{d t^{2}}\left[\sum _ { n = 0 } ^ { M - 1 } \sum _ { j = 1 } ^ { m = 3 } \frac { \hat { w } _ { ( j ) , ( P _ { b s } ) } ( L _ { b } / 2 , t ) } { 1 - { } ^ { ( c ) } \alpha _ { ( j ) } ^ { 2 } } \left(\sin ^{(c)} \Omega_{(j) d r}\left(t-\frac{d_{b g, n}}{c}\right)-\right.\right. \\
& \left.\left.-{ }^{(c)} \alpha_{(j)} \sin \omega_{(j)}\left(t-\frac{d_{b g, n}}{c}\right)\right) \sin \frac{j \pi x}{2} H_{(n)}\right]= \\
& =\sum_{n=0}^{M-1} \sum_{j=1}^{m=3} \frac{\hat{w}_{(j),\left(P_{b s}\right)}\left(L_{b} / 2, t\right)}{1-{ }^{(c)} \alpha_{(j)}^{2}}\left(-{ }^{(c)} \Omega_{(j) d r}^{2} \sin ^{(c)} \Omega_{(j) d r} .\right. \\
& \left.\cdot\left(t-\frac{d_{b g, n}}{c}\right)+{ }^{(c)} \Omega_{(j) d r} \omega_{(j)}\left(t-\frac{d_{b g, n}}{c}\right)\right) \sin \frac{j \pi x}{2} H_{(n)}
\end{aligned}
$$

For: $\frac{d_{b g, n}}{c} \leq t \leq \frac{d_{b g, n}}{c}+\frac{L_{b}}{c}$,

$H_{(n)}=H\left(t-\frac{d_{b g, n}}{c}\right)-H\left(t-\frac{d_{b g, n}}{c}-\frac{L_{b}}{c}\right)$,

where:

$\hat{w}_{(j),\left(P_{b s}\right)}\left(L_{b} / 2\right) \equiv \hat{q}_{(j),\left(P_{b s}\right)}\left(L_{b} / 2\right)=\frac{2 P_{b g} L_{b}^{3}}{E I \pi^{4}} \approx \frac{P_{b g} L_{b}^{3}}{48 E I}$

is the static deflection at mid-span caused by the load $P_{b g}$ with respect to the $j$ th mode of vibrations, ${ }^{(c)} \Omega_{(j) d r}=\frac{j \pi c}{L_{b}}$ is the $j$ th circular driving frequency of the force $P_{b g^{\prime}}$ $\omega_{(j)}=\frac{j^{2} \pi^{2}}{L_{b}^{2}} \sqrt{\frac{E I}{\bar{m}_{1}}}\left[\mathrm{~s}^{-1}\right]$ is the $j$ th natural frequency of the beam, ${ }^{\left({ }^{c)}\right.} \alpha_{(j)}=\frac{{ }^{(c)} \Omega_{(j) d r}}{\omega_{(j)}}=\frac{j \pi c}{L_{b} \omega_{(1)}} \equiv \frac{c}{c_{c r}}$ is the dimensionless speed parameter corresponding to the $j$ th mode of vibrations.

B) Component of the acceleration ${ }^{(c)} \ddot{w}_{(j),\left(P_{b, n}, n\right.}^{B}\left(L_{b} / 2, t\right)$ corresponding to the free vibrations response of the beam for the $j$-th mode and for $n=1,2,3, \ldots . K$ loads moving out the beam after they have left the beam (the damping of the beam is considered) can be expressed as:

$$
\begin{aligned}
& { }^{(c)} \ddot{\mathcal{W}}_{(j),(P b g, n)}^{(B)}\left(L_{b} / 2, t\right)=\frac{d^{2}}{d t^{2}}\left[{ }^{(c)} \boldsymbol{w}_{(j),\left(P_{b, n}\right)}^{(B)}\left(L_{b} / 2, t\right)\right]= \\
& =\frac{d^{2}}{d t^{2}}\left[\frac{\hat{w}_{(j) s t,\left(P_{b s}\right)}\left(L_{b} / 2\right)}{1-{ }^{\left({ }^{c}\right.} \alpha_{(j)}^{2}} \sum_{n=0}^{K-1} \sum_{j=1}^{m=3}-e^{-\omega_{d}\left(t-\frac{d_{n g, n}}{c}-\frac{L_{b}}{c}\right)^{(c)}}\right. \\
& \left.\alpha_{(j)} \sin \omega_{(j)}\left(t-\frac{d_{b g, n}}{c}-\frac{L_{b}}{c}\right) \sin \frac{j \pi}{2} H_{\left(n^{*}\right)}(t)\right]= \\
& =\frac{\hat{w}_{(j) s t,\left(P_{b s}\right)}\left(L_{b} / 2, t\right)}{1-{ }^{(c)} \alpha_{(j)}^{2}} \sum_{n=0}^{K-1} \sum_{j=1}^{m=3}-e^{-\omega_{d}\left(t-\frac{d_{n g, n} n}{c}-\frac{L_{b}}{c}\right)^{(c)}} \Omega_{(j) d r}^{2} \omega_{(j)} \\
& \sin \omega_{(j)}\left(t-\frac{d_{b g, n}}{c}-\frac{L_{b}}{c}\right) \sin \frac{j \pi}{2} H_{\left(n^{*}\right)}(t)
\end{aligned}
$$

For: $\frac{d_{b g, n}}{c}+\frac{L_{b}}{c} \leq t \leq \frac{d_{b g, n}}{c}+\frac{L_{b}}{c}+\Delta t$,

$H_{\left(n^{*}\right)}(t)=\left(\theta\left(t-\frac{d_{b g, n}}{c}-\frac{L_{b}}{c}\right)-\theta\left(t-\frac{d_{b g, n}}{c}-\frac{L_{b}}{c}-\Delta t\right)\right)$,

$\Delta t$ is a selected time of the beam free vibrations of the beam.

\section{Numerical studies for the mid-point vertical acceleration of the railway steel bridge $L_{b}=38 \mathrm{~m}$ for the speed $c=65 \mathrm{~m} / \mathrm{s}=234 \mathrm{~km} / \mathrm{h}$}

To verify the theoretical expressions, the numerical study has been performed. The mid-point acceleration response of the bridge $L_{b}=38 \mathrm{~m}$ during the passage of the passenger train with the eight IC-cars $\left(16 \mathrm{x} P_{b g}=16 \times 256 \mathrm{KN}\right)$, the length of $\operatorname{car} d_{v}=24.5 \mathrm{~m}$, and for the resonance speed $c_{\text {res(2) }}=65.03 \mathrm{~m} / \mathrm{s}=234.16 \mathrm{~km} / \mathrm{h}$ have been analysed.

\section{Input parameters of the solution:}

The bending stiffness of the beam: $E I=7.58 \cdot 10^{7} \mathrm{kNm}^{2}$, the mass $m_{1}=m_{1(B c)}+m_{1(S u p)}=3.18 \mathrm{t} / \mathrm{m}$, the circular frequencies of the bridge: $\omega_{(1)}=33.34 \mathrm{~s}^{-1}, \omega_{(3)}=300.06 \mathrm{~s}^{-1}$, the driving frequencies ${ }^{\left({ }^{c=65)}\right.} \Omega_{(1) d r}=\frac{\pi c}{L_{b}}=5.3711 \mathrm{~s}^{-1}$, 


$$
\begin{aligned}
& \text { a) Components } \\
& { }_{(c=65)} \ddot{W}_{(j=1) s t,\left(P_{b, n}\right)}\left(L_{b} / 2, t\right)-\text { the blue colour } \\
& { }^{\left({ }^{c}=65\right)} \ddot{W}_{(j=1) d y n,\left(P_{b, n}\right)}\left(L_{b} / 2, t\right)-\text { the red colour }
\end{aligned}
$$

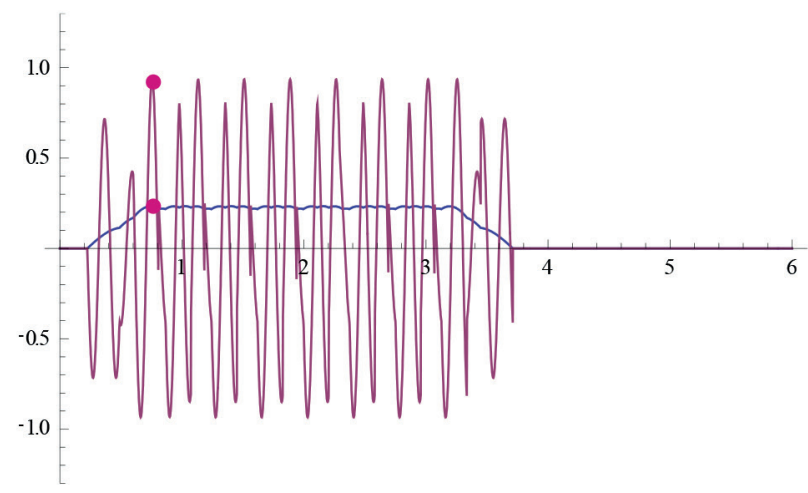

b) Total component

$$
{ }^{(c=65)} \ddot{W}_{(j=1),\left(P_{b 8} 11 \ldots+P_{b 8} 82\right)}^{(A)}\left(L_{b} / 2, t\right)
$$

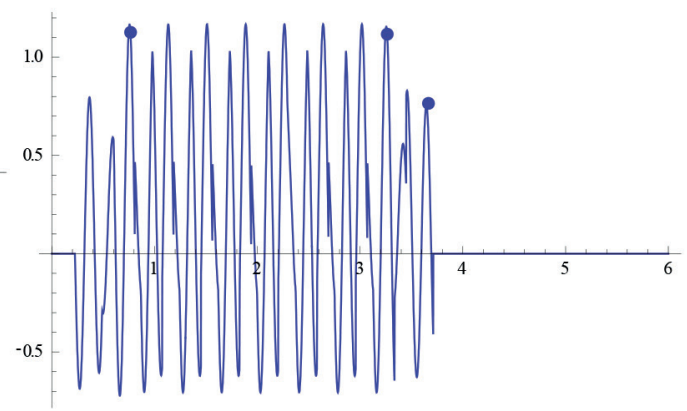

$$
\begin{gathered}
\text { Axes: } x=t[s], y=\text { Acceleration }\left[\mathrm{m} / \mathrm{s}^{2}\right] \\
\text { Amplitudes: }{ }^{{ }^{(c=65)} \hat{\ddot{w}}_{(j=1) s t}\left(L_{b} / 2, t\right)=0.23 \mathrm{~m} / \mathrm{s}^{2}} \quad{ }_{\left({ }^{2}=65\right)} \hat{\ddot{w}}_{(j=1)}^{(A)}\left(L_{b} / 2, t\right)=1.16 \mathrm{~m} / \mathrm{s}^{2} \\
{ }^{(c=65)} \hat{\ddot{w}}_{(j=1) d y n}^{(1)}\left(L_{b} / 2, t\right)=0.91 \mathrm{~m} / \mathrm{s}^{2}
\end{gathered}
$$

Figure 5 Acceleration response ${ }^{(c=65)} \ddot{w}_{(j=1) s t,\left(P_{b, n}\right)}^{(A)}\left(L_{b} / 2, t\right)$ and its components.

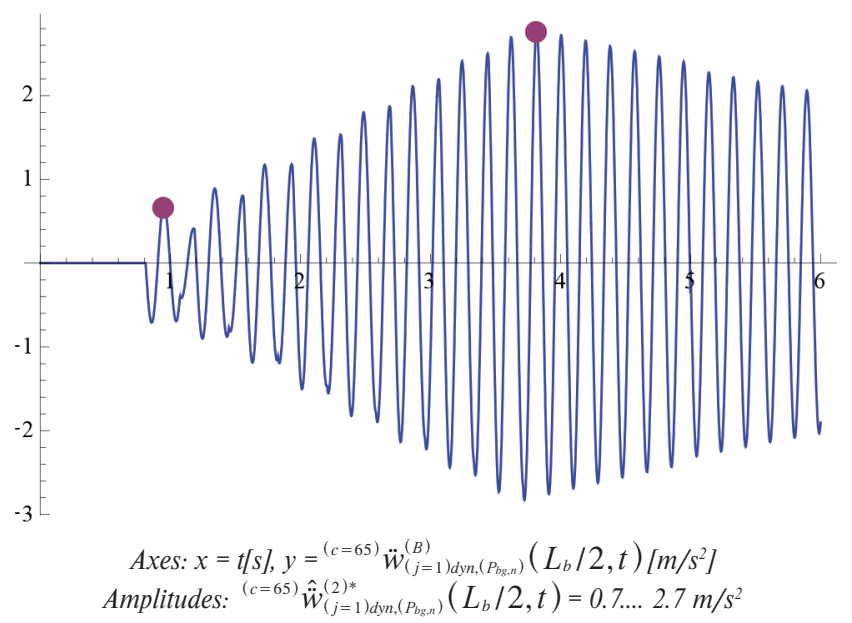

Figure 6 Acceleration response ${ }^{(c=65)} \ddot{w}_{(j=1) d y n,\left(P_{b, n}\right)}^{(B)}\left(L_{b} / 2, t\right)$ for $t=0 \div 6.0 \mathrm{~s}$.

${ }^{\left({ }^{c=65)}\right.} \Omega_{(3) d r}=\frac{3 \pi c}{L_{b}}=16.1133 \mathrm{~s}^{-1}, \quad$ the non-dimensional speed parameters ${ }^{\left({ }^{c=65)}\right.} \alpha_{(3)}=\frac{\Omega_{(3) d r}}{\omega_{(3)}}=0.1611$, the damping coefficient $\omega_{d}=f_{(\text {damp })} \vartheta=\frac{\omega_{(1)}}{2 \pi} \vartheta=\frac{33.34}{6.26} 0.025=0.1327 \mathrm{~s}^{-1}$.

Results of the analysis are presented in the time domain [9]. Vertical midpoint acceleration of the beam ${ }^{(c)} \ddot{w}_{(j),\left(P_{b, n}\right)}^{(A)}\left(L_{b} / 2, t\right)$ due to the loads moving over the beam for $j=1$, Equation (11), are presented in Figures 5 to 7 and result ${ }^{(c)} \ddot{w}_{(j),\left(P_{b, n}, n\right.}^{(B)}\left(L_{b} / 2, t\right)$ for $j=$ $1+3$, Equation (12), are presented in Figures 8 to 9. Comparison is presented in Figures 10 to 11.

\subsection{Vertical midpoint acceleration of the beam due} to the loads moving over the beam for $j=1$

This response includes the two components:
1) The forced vibrations part (the quasi-static component of

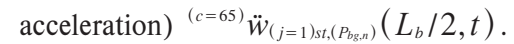

2) The free vibrations part (the dynamic component) ${ }^{(c=65)} \ddot{w}_{(j=1) d y n,\left(P_{b, n}\right)}\left(L_{b} / 2, t\right)$, for $j=1$, Equation (11), for the time section $t=0 \div 6.0 \mathrm{~s}$, Figure 5 .

\subsection{Free vibrations response of the beam due to the loads moving out the beam for $j=1$}

The time history of the vertical acceleration of the beam ${ }^{(c=65)} \ddot{W}_{(j=1),\left(P_{b, n}\right)}^{(B)}\left(L_{b} / 2, t\right)$, for the mode shape $j=1$, corresponds to loads $P_{b, n}, n=1,2,3, \ldots . K$ moving out the beam after they have left the span (Equation 12), for the time section $t=0 \div 6.0$ s, is in Figure 6. 
a) Components
${ }^{(c)} \ddot{w}_{(j),\left(P_{b, n}\right)}^{(A)}\left(L_{b} / 2, t\right)$ - the blue colour
${ }^{(c)} \ddot{w}_{(j) d y n,\left(P_{b, n}\right)}^{(B)}\left(L_{b} / 2, t\right)$ - the red colour

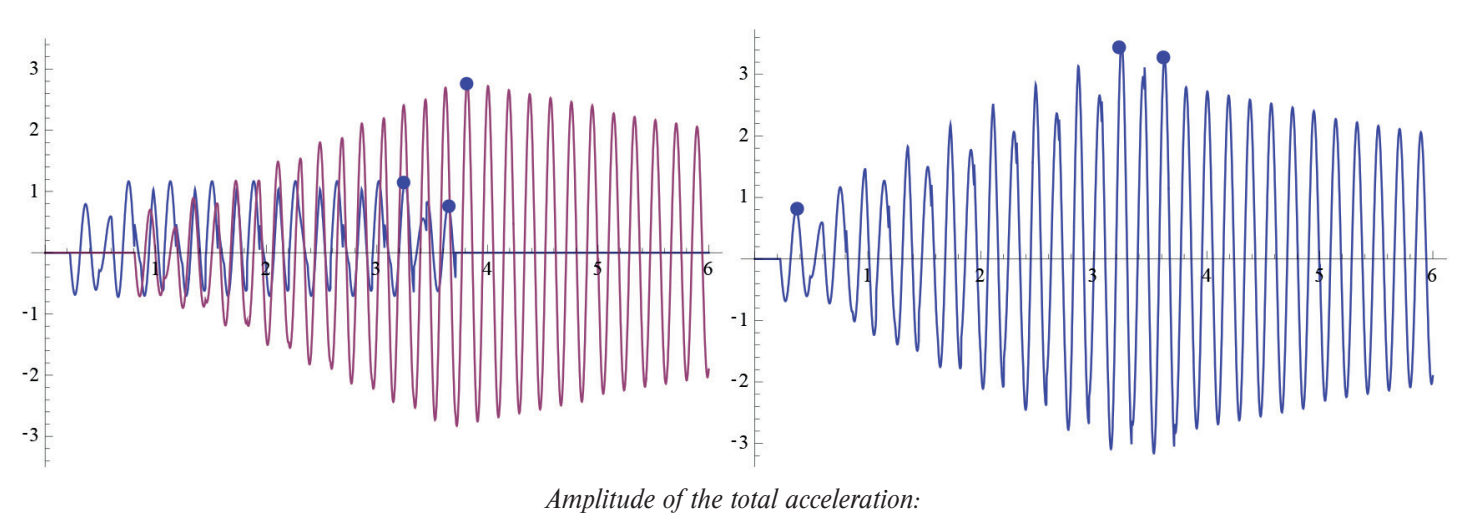

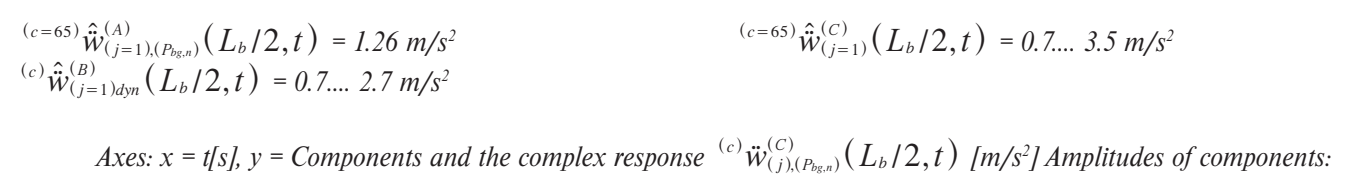

c) Detail of the response for $t=3.0 \div 4.5 \mathrm{~s}$

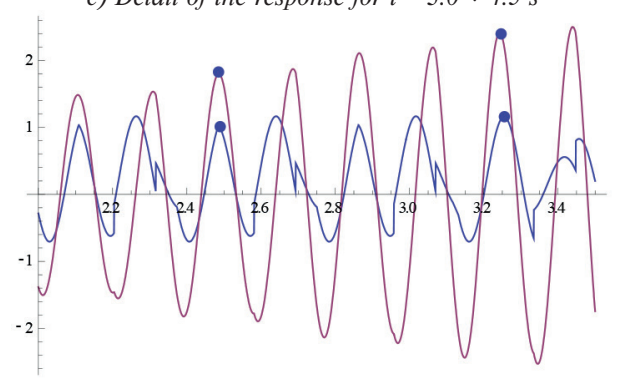

Figure 7 Complex acceleration ${ }^{(c=65)} \ddot{w}_{(j=1),\left(P_{b, n}\right)}^{(C)}\left(L_{b} / 2, t\right)$ and its components, for $j=1$

4.3 Complex acceleration response due to the loads moving over the beam and the loads moving out the beam for $j=1$

The complex response ${ }^{(c)} \ddot{w}_{(j),\left(P_{b, n}\right)}^{(C)}\left(L_{b} / 2, t\right)$ obtains by superposition (Equation 10):

$$
\begin{aligned}
& { }^{(c)} \ddot{\boldsymbol{w}}_{(j),\left(P_{b, n}, n\right.}^{(C)}\left(L_{b} / 2, t\right)={ }^{(c)} \ddot{\boldsymbol{w}}_{(j),\left(P_{b, n}\right)}^{(A)}\left(L_{b} / 2, t\right)+ \\
& +{ }^{(c)} \ddot{\boldsymbol{w}}_{(j) d y n,\left(P_{b_{b}, n}\right)}^{(B)}\left(L_{b} / 2, t\right)
\end{aligned}
$$

Results of the solution for the time section $t=0 \div 6.0 \mathrm{~s}$, are shown in Figure 7.

\subsection{Vertical midpoint acceleration of the beam due to the loads moving over the beam, for $j=1+3$}

The midpoint acceleration ${ }^{\left({ }^{(}=65\right)} \ddot{\boldsymbol{w}}_{(j=1+3),\left(P_{b_{g}, n}\right)}^{(A)}\left(L_{b} / 2, t\right)$ for the modes $j=1+3$ obtains by superposition and includes the two components:

1) The forced vibrations part (the quasi-static component) ${ }^{(c=65)} \ddot{w}_{(j=1+3) s t,\left(P_{b, n}\right)}\left(L_{b} / 2, t\right)$.

2) The free vibrations part (the dynamic component) ${ }^{(c=65)} \ddot{w}_{(j=1+3) d y n,\left(P_{b, n},\right)}\left(L_{b} / 2, t\right)$, for $j=1+3$. The solution for the time section $t=0 \div 6.0 \mathrm{~s}$, is shown in Figure 8 .
4.5 Acceleration due to loads moving out the beam - the residual acceleration for $j=1+3$

Comparison of the residual free vibrations acceleration

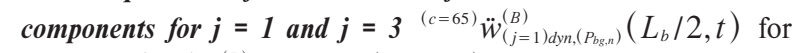
$j=1$ and ${ }^{(c=65)} \ddot{w}_{(j=1+3) d y n,\left(P_{b, n}\right)}^{(B)}\left(L_{b} / 2, t\right)$ for $j=1+3$, Figure 9.

$$
\begin{aligned}
& { }^{(c=65)} \ddot{\boldsymbol{w}}_{(j=1+3) d y y_{n}\left(P_{b_{B}, n}\right)}^{(B)}\left(L_{b} / 2, t\right)={ }^{(c=65)} \ddot{\boldsymbol{W}}_{(j=1) d y n,\left(P_{b, n}\right)}^{(B)}\left(L_{b} / 2, t\right)+ \\
& +{ }^{(c=65)} \ddot{W}_{(j=3) d y n,\left(P_{b_{b}, n}\right)}^{(B)}\left(L_{b} / 2, t\right)
\end{aligned}
$$

\subsection{Comparison of accelerations for modes of vibrations}

$$
j=1 \text { and } j=1+3
$$

A) Comparison of the residual total free vibrations ${ }_{(c=65)} \ddot{W}_{(j=1) d y n,\left(P_{b s, n}\right)}^{(B)}\left(L_{b} / 2, t\right)$ for $j=1$ and ${ }^{(c=65)} \ddot{w}_{(j=1+3) d y n,\left(P_{b, n}\right)}^{(B)}\left(L_{b} / 2, t\right)$ for $j=1+3$, Figure 10.

B) Complex acceleration due to the loads moving over the beam and the loads moving out the beam, for $j=1+3$ The complex acceleration response

${ }^{(c=65)} \ddot{w}_{(j=1+3) d y n,\left(P_{b, n}\right)}^{(C)}\left(L_{b} / 2, t\right)$ for the modes $j=1+3$, is obtained by superposition:

1) For the loads moving over the beam. 
a) Components

${ }^{(c=65)} \ddot{W}_{(j=1+3) s t,\left(P_{b, n}\right)}\left(L_{b} / 2, t\right)-$ the blue colour
${ }^{(c=65)} \ddot{W}_{(j=1+3) d y n,\left(P_{b p, n}\right)}\left(L_{b} / 2, t\right)-$ the red colour

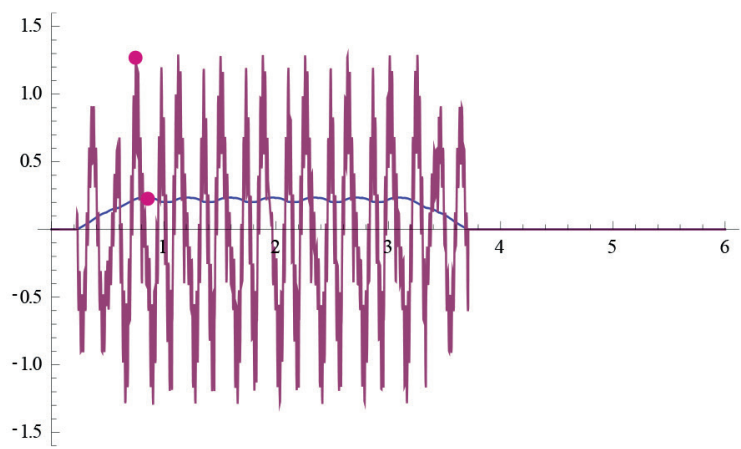

b) Total component

${ }^{(c=65)} \ddot{W}_{(j=1+3),\left(P_{b, n}\right)}^{(A)}\left(L_{b} / 2, t\right)$

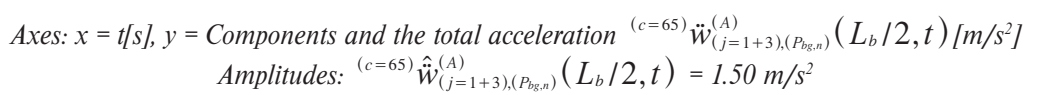

Figure 8 Components and total acceleration ${ }^{(c=65)} \ddot{w}_{(j=1+3),\left(P_{b, n}\right)}^{(A)}\left(L_{b} / 2, t\right)$ for $j=1+3$

a) Components

${ }^{(c=65)} \ddot{w}_{(j=1) d y n,\left(P_{b, n}\right)}^{(B)}\left(L_{b} / 2, t\right)$ - the red colour

${ }^{(c=65)} \ddot{w}_{(j=1+3) d y n,\left(P_{b, n}, n\right)}^{(B)}\left(L_{b} / 2, t\right)$ - the blue colour

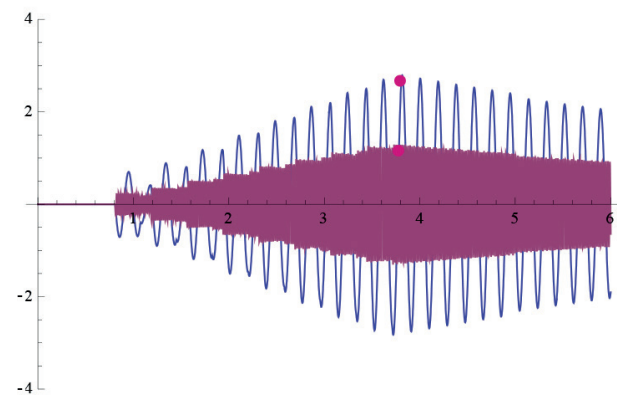

Amplitudes of parts:

${ }^{(c=65)} \hat{\ddot{W}}_{(j=1)}^{(B)}$

${ }^{(c=65)} \hat{\ddot{W}}_{(j=3) d}^{(B)}$

$x=t[s], y=$ Parts and the total acceleration

$\left(L_{b} / 2, t\right)$ - the blue colour

$\left(L_{b} / 2, t\right)$ - the dark red colour

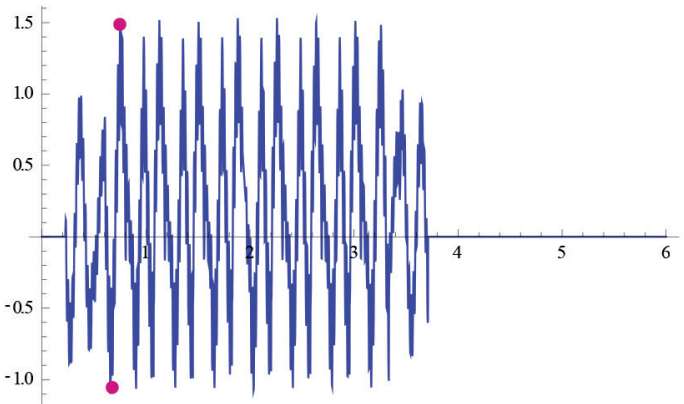

b) Total component

${ }^{(c=65)} \ddot{w}_{(j=3) d y n,\left(P_{b, n}, n\right)}^{(B)}\left(L_{b} / 2, t\right)$

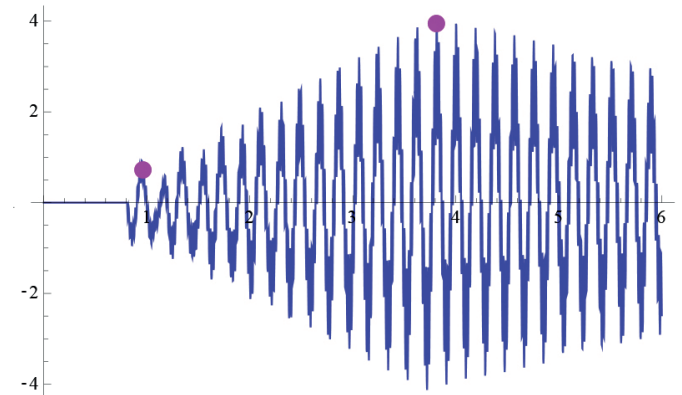
Total amplitudes:

${ }^{(c=65)} \ddot{\mathcal{W}}_{(j=1+3) d y n,\left(P_{b, n}\right)}^{(2) *}\left(L_{b} / 2, t\right)=0.86 \div 4.02 \mathrm{~m} / \mathrm{s}^{2}$

Figure 9 Acceleration ${ }^{\left({ }^{c=65)}\right.} \ddot{w}_{(j=1+3) d y n,\left(P_{b B, n}\right)}^{(B)}\left(L_{b} / 2, t\right)$ corresponding to the free vibrations and its parts

a) Residual accelerations for the mode $j=1$

${ }^{4}$

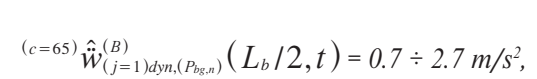




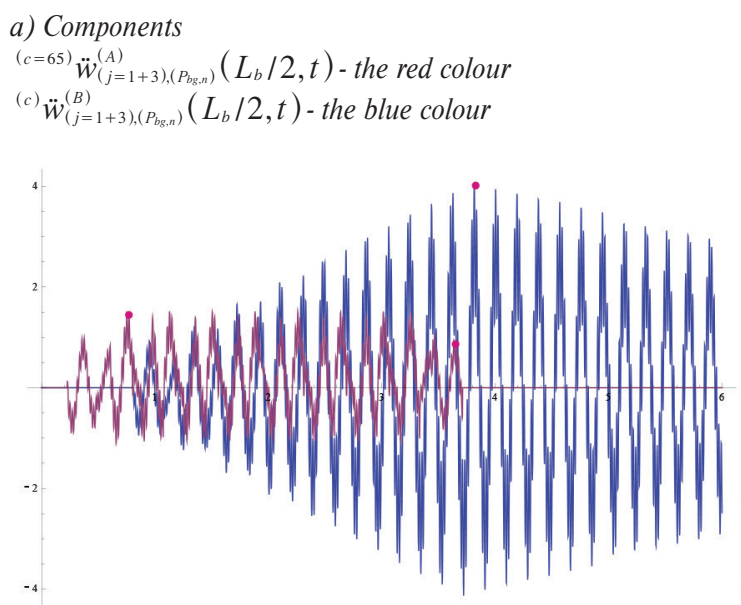

$$
\begin{aligned}
& \text { b) Total component } \\
& { }_{(c=65)} \ddot{W}_{(j=1+3),\left(P_{b s, n}\right)}^{(C)}\left(L_{b} / 2, t\right)
\end{aligned}
$$

c) Detail superposition for $t=3.0 \div 4.5 \mathrm{~s}$

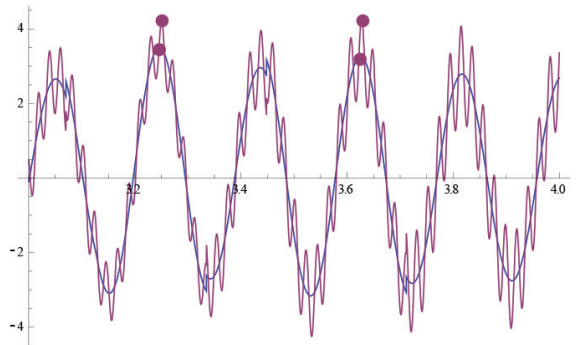

$$
\begin{gathered}
\text { Axes: } x=t[s], y=\text { Parts and the total component }{ }^{(c)} \ddot{w}_{(j),\left(P_{b, n}\right)}^{(c)}\left(L_{b} / 2, t\right)\left[\mathrm{m} / \mathrm{s}^{2}\right] \\
\text { Amplitudes: }{ }^{(c=65)} \hat{\tilde{w}}_{(j=1+3)}^{(A)}\left(L_{b} / 2, t\right)=1.27 \mathrm{~m} / \mathrm{s}^{2} \quad{ }^{(c=65)} \hat{\tilde{w}}_{(j=1+3)}^{(c)}\left(L_{b} / 2, t\right)=1.0 \div 4.3 \mathrm{~m} / \mathrm{s}^{2}
\end{gathered}
$$

Figure 11 The complex response ${ }^{(c=65)} \ddot{w}_{(j=1+3),\left(P_{b, n}\right)}^{(C)}\left(L_{b} / 2, t\right)$ for $t=0 \div 6.0 \mathrm{~s}$ and for $t=3.0 \div 4.5 \mathrm{~s}$

2) For the loads moving out the beam, for the time section $t=0$ $\div 6.0 \mathrm{~s}$, Figures $11 \mathrm{a}$ ), b), and for the time segment $t=3.0 \div$ $4.5 \mathrm{~s}$, Figure $11 \mathrm{c}$.

$$
\begin{aligned}
& { }^{(c=65)} \ddot{W}_{(j=1+3),\left(P_{b 8} 11 \ldots+P_{b 882}\right)}^{(C)}\left(L_{b} / 2, t\right)= \\
& ={ }^{(c=65)} \ddot{\boldsymbol{W}}_{(j=1+3),\left(P_{b_{b} 11 \ldots+}(A)+P_{b 8} 82\right)}\left(L_{b} / 2, t\right)+ \\
& +{ }^{(c=65)} \ddot{W}_{(j=1+3)\left(P_{b y} 1 \ldots+P_{b 882}\right)}^{(2 *}\left(L_{b} / 2, t\right)
\end{aligned}
$$

\section{Conclusions}

The vertical mid-point acceleration for the resonant speed $c=65 \mathrm{~m} / \mathrm{s}=234 \mathrm{~km} / \mathrm{h}$ for the simply supported railway bridge of the length $L_{b}=38 \mathrm{~m}$ subjected to the loads by conventional IC passenger trains with eight cars, running on the Slovak railways lines (Figure 1) has been investigated through numerical simulation. Since the maximum acceleration is expected at the mid-point of the beam, the acceleration response-was focused on the mid-point response $x=L_{b} / 2$. The closed form of solution has been applied.

The numerical study was focused to:

1) Evaluating the influence of the free and forced vibrations components on the total acceleration.

2) The influence of mode vibrations $j=1$ and $j=1+3$ on the total acceleration.

3) The serviceability limit state for the bridge deck acceleration [8] was controlled.
The following conclusions can be drawn:

1) Dynamic response components, due to forced vibrations, increase with speed. When the running speed of moving loads $c$ coincides with any of the resonant speeds $c_{(k) \text { res }}$ the sum of the free vibrations response components generated by each moving force $P_{b g, n}$ is determining part of the acceleration response. The total response due to a series of moving loads is the sum of response to each moving load. If the number of vehicles is sufficiently large, the acceleration response may occur. If the number of vehicles is small, the acceleration response may not occur. The most unfavourable effect in the response causes the moving loads when the last force $P_{\mathrm{n}}$ passes through the bridge and the other forces $\left(P_{1} \div P_{(n-l)}\right)$ have already left the bridge.

2) The fundamental mode $j=1$ provides the largest contribution to the midpoint acceleration, but at least the third mode must also be taken into account. The third mode of vibrations $j=3$ have also significant influence on the acceleration amplitude, especially for bridges with light damping. The analysis showed that the impact of the mode of vibrations $j=3$ reaches up to $31 \%$, therefore the mode $j=3$ cannot be neglected.

3) The maximally acceptable value of the acceleration of the bridge in terms of EN1991-2, for direct fastened tracks must fulfil the condition ${ }^{(c)} \ddot{w}(x, t)_{\max }<5 \mathrm{~m} / \mathrm{s}$. The aforementioned simulation, for the resonant speed $c=65 \mathrm{~m} / \mathrm{s}=234 \mathrm{~km} / \mathrm{h}$, gives the acceleration amplitude ${ }^{(c=65)} \hat{\tilde{w}}_{(j=1) d y n}^{(c)}\left(L_{b} / 2, t\right)=4.2 \mathrm{~m} / \mathrm{s}^{2}$. For the cancellation 
speed $c=57 \mathrm{~m} / \mathrm{s}=205 \mathrm{~km} / \mathrm{h}$ gives the acceleration amplitude ${ }^{(c=57)} \hat{\tilde{w}}_{(j=1)}^{(C)}\left(L_{b} / 2, t\right)=1.2 \mathrm{~m} / \mathrm{s}^{2}$.

\section{Acknowledgments}

This study was supported by the Grant VEGA No. 1/0336/15 and No. 2/0033/15 of the Grant Agency of the Slovak Republic.

\section{References}

[1] KOLOUSEK, V. Dynamics of structures I. (in Czech). Monograph. Praha: SNTL, 1954, p. 263.

[2] BIGGS, J. M. Structural mechanics. Monograph. New York, NY: McGraw-Hill, 1964. ISBN 07005255-7.

[3] YEONG-BIN, Y., et al. Vibrations of simple beams due to trains moving at high speeds. Engineering Structures [online]. 1997, 19(11), p. 936-944. ISSN 0141-0296/eISSN 1873-7323. Available from: https://doi.org/10.1016/S0141-0296(97)00001-1

[4] XIA., H., et al. Vibrations resonance and cancellation of simply supported bridges under moving train loads. Journal of Engineering Mechanics [online]. 2014, 140, p. 1-11. ISSN 0733-9399/eISSN 1943-7889. Available from: https://doi.org/10.1061/(ASCE)EM.19437889.0000714

[5] NAPRSTEK, J. Resonance speeds of axle forces row moving along a beam (in Czech). Colloquium "Dynamics of machines 2000". ASCR Prague, 2000, p.145-152

[6] LI J., SU M. The resonant vibrations for a simply supported girder bridge under high-speed trains. Journal of Sound and Vibration [online]. 1999, 224(5), p. 897-915. ISSN 0022-460X. Available from: https://doi.org/doi.org/10.1006/jsvi.1999.2226

[7] MORAVCIK, M., MORAVCIK, M. Resonance vibrations of railway bridges subjected to passing vehicles. Communications Scientific Letters of the University of Zilina [online]. 2017, 19(3), p. 96-101. ISSN 1335-4205/eISSN 2585-7878. Available from: http:// komunikacie.uniza.sk/index.php/communications/article/view/241

[8] STN 1991-2. Slovak standard (in Slovak). The European Standard 1991-2, Actions on structures - part 2, 2006.

[9] Wolfram Mathematica10.0. Program system for technical computing. Wolfram Computation Meets Knowledge [online]. Available from: https://www.wolfram.com/mathematica 